\title{
A distal renal tubular acidosis showing hyperammonemia and hyperlactacidemia
}

\author{
Un cass di acidosi tubulare renale distale ad esordio con iperammoniemia e iperlattacidemia
}

C. Ripoli, ${ }^{1}$ A. Pinna, ${ }^{1}$ S. Marras,${ }^{1}$ M.L. Fenu, ${ }^{1}$ A.M. Nurchi ${ }^{1}$

Key words: distal tubular acidosis, hyperammonemia, lactate increase, genetic tests

\begin{abstract}
Introduction: distal renal tubular acidosis (dRTA) presents itself with variable clinical manifestations and often with late expressions that impact on prognosis.

Case report: A 45-day-old male infant was admitted with stopping growth, difficult feeding and vomiting after meals. Clinical tests and labs revealed a type 1 renal tubular acidosis, even if the first blood tests showed ammonium and lactate increase. We had to exclude metabolic diseases before having a certain diagnosis.

Conclusions: blood and urine investigations and genetic tests are fundamental to formulate dRTA diagnosis and to plan follow-up, according to possible phenotypic expressions of recessive and dominant autosomal forms in patients with dRTA.
\end{abstract}

\section{Introduction}

The term "renal tubular acidosis", first used by Pines and Mudge in $1951,{ }^{1}$ identifies a group of disorders characterized by metabolic acidosis, secondary to bicarbonate tubular reabsorption defect and/or renal hydrogen ions secretion defect. Tubular acidosis is characterised by hyperchloremic metabolic acidosis with normal plasmatic anion gap and glomerular function substantially preserved. ${ }^{2}$

\footnotetext{
Dipartimento di Scienze Pediatriche e Medicina Clinica, Istituto di Clinica Pediatrica "G. Macciotta", Università di Cagliari; I I Clinica Pediatrica, Università degli Studi di Cagliari
}

RTA may be primitive (genetic) ${ }^{3}$ or secondary to systemic pathologies or to drug and toxic substances intake.

Distal renal tubular acidosis (type 1 or dRTA) is caused by a deficient distal renal acidification mechanism. ${ }^{4}$ Primitive dRTA exists in three main variants, according to transport protein involvement and clinical presentation: autosomal dominant form and recessive form (that can occur with or without neurosensory hearing loss) 5,6 (Tab1). Distal renal tubular acidosis presents itself with variable severity of metabolic acidosis typically associated with hypokalemia, hypercalciuria and hypocitraturia. Rickets and osteomalacia can occur both in dominant and recessive forms. The former are generally milder and have a later onset in childhood and adulthood, the latter may arise over the first few months of life with stopping growth. Nephrocalcinosis and nephrolithiasis are frequent. Recessive forms may show neurosensory hearing loss that can be present since the early months of life or later until adulthood.

As described later on, clinical manifestations and the prognosis of the genetic form of dRTA are related both to the gene involved and the mutation type. Diagnosis of distal renal tubular acidosis is confirmed by urine alkalinity within a systemic metabolic acidosis framework. Treatment with oral bicarbonate and/or citrate is able to correct metabolic acidosis, bone abnormalities and impaired growth, but is not effective in modifying or preventing neurosensory hearing loss. ${ }^{7}$ Aside from complete forms of dRTA, the so called "incomplete" forms (idRTA), characterized by a distal urine acidification deficit, albeit without systemic metabolic acidosis, are becoming increasingly common. In these forms, which may manifest themselves as recurrent nephrolithiasis, rickets resistance to therapy, growth deficit, the distal tubular defect is shown by the absence of urine acidification $(\mathrm{pH}<5,5)$ after oral load of ammonium chloride. ${ }^{8-9}$

\section{Case report}

A 45-day-old infant was referred to our clinic from the attending pediatrician for stopping growth. He was born at term, by caesarean section for breech presentation. Apgar score, at the first
Indirizzo per la corrispondenza (Corresponding author):

Presidio Pediatrico Macciotta, Ospedale San Giovanni di Dio,

via Porcell, 3 , 09124 Cagliari

tel. reparto 0706093493

tel. segreteria ospedaliera ed universitaria 0706093486

fax 0706093482

email: annapaola_pinna@yahoo.it 
minute, was 8 , then 10 at the fifth minute. Weight at birth was $2.950 \mathrm{Kg}$. Over two weeks of life he received artificial feeding and his weight upon hospitalization was $3.150 \mathrm{Kg}$ (post-natal growth of $190 \mathrm{~g}$ ). Parents reported that their baby fed with difficulty and sporadically presented vomiting after meals. He was admitted in bad general conditions with adipose and muscular mass scant trophism, reduced skin turgescence and elasticity, accompanied by modest plagiocephaly. Anterior fontanelle was normal, with intact sensory functions and absence of hyporeactivity or meningeal signs.

Upon hospitalization, $\mathrm{CBC}$ didn't show any significant alterations, whereas a few days later we noticed the appearance of hypochromic anemia. Blood glucose level was normal $(3.9 \mathrm{mmol} / \mathrm{L})$, liver and kidney functions were preserved. Inflammatory indicators were negative, and blood tests showed hypokalemia $(2.6 \mathrm{mmol} / \mathrm{L})$, hyperchloremia (up to $117 \mathrm{mmol} / \mathrm{L}$ ), normal natremia (139 $\mathrm{mmol} / \mathrm{L})$, hypercalcemia $(3.05 \mathrm{mmol} / \mathrm{L})$ and a phosphate value of $2.38 \mathrm{mmol} / \mathrm{L}$. At first, blood-gas analysis showed a metabolic acidosis with $\mathrm{pH} 7.25, \mathrm{HCO}_{3}^{-} 13.6 \mathrm{mmol} / \mathrm{L}, \mathrm{EB}-14.4$ and 16.4 $\mathrm{mmol} / \mathrm{L}$ of anion gap $\left[\left(\mathrm{Na}^{+}-\left(\mathrm{Cl}^{-}+\mathrm{HCO}_{3}^{-}\right)\right]\right.$.

Urine tests detected modest proteinuria, leukocyturia and hemoglobin traces, urinary $\mathrm{pH}$ was 7 and sediment presented several amorphous phosphate granules in addition to various exfoliation epithelial cells.

Urine culture was negative. Some urine electrolytes were modestly increased such as natriuria and kaliuria, while hypercalciuria was quite high (calcium/creatinine ratio 0.97).

An increase in lactate $(7.5 \mathrm{mmol} / \mathrm{L})$ and hyperammonemia ${ }^{10}(66$ $(\mu \mathrm{mol} / \mathrm{L})$ was noted, which made us suspect the presence of an underlying metabolic disease .

However, urine organic acids, urinary amino acids, blood amino acids, and pyruvate showed no significant alterations for diagnosis. Transfontanellar and gastroesophageal ultrasonography were normal, while renal ultrasonography showed a marked increase of echogenicity, completely covering all renal pyramids, attributable to medullary nephrocalcinosis (Fig. 1). Slit lamp examina-

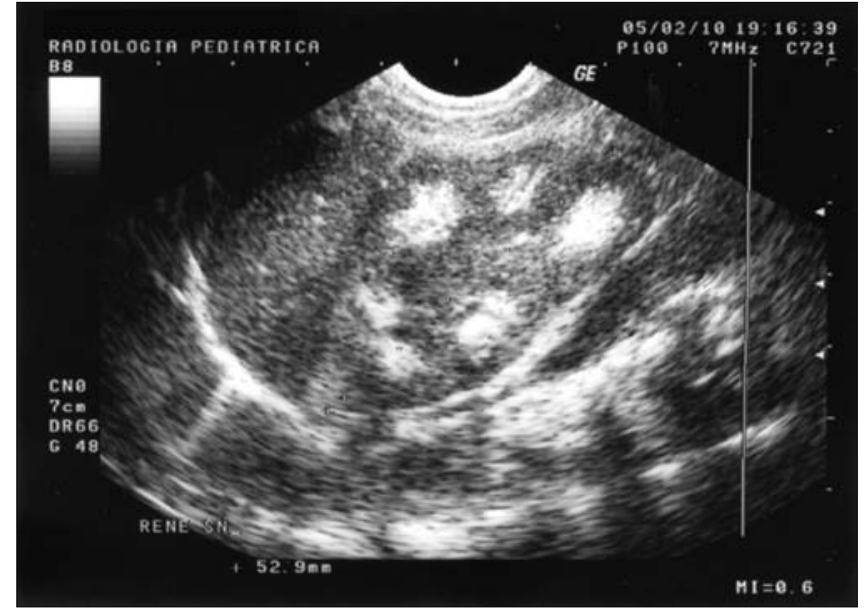

Figure 1.

Renal ultrasonograph of the infant's left kidney showing markedly increase of ecogenicity , expression of medullary nephrocalcinosis.

tion revealed transparent lens and cornea; besides, the eye ground was normal. Audiometric screening (accuscreen) seemed to be negative. Since our patient was strongly considered to have a distal renal tubular acidosis owing to impaired growth, growth retardation, and blood alterations, we planned genetic investigations in order to find the mutation type responsible for clinical signs. Additionally, we ordered a corrective treatment with intravenous paediatric hydration (dextrose 5\% and sodium bicarbonate) and $\mathrm{KCl}$, followed by oral therapy with sodium bicarbonate $(3 \mathrm{mmol} / \mathrm{Kg} /$ day) and potassium citrate (equivalent to 2 $\mathrm{mmol} / \mathrm{Kg} /$ day tripotassium citrate monohydrate) that determined an improvement of blood values and general conditions (resumption of growth and increase in weight).

Moreover our patient received iron therapy for sideropenic anaemia and gastroprotective drugs for regurgitation associated with potassium therapy. Sodium and potassium citrate doses were constantly changed during follow-up according to clinical needs, electrolytic modifications and auxological indices.

\begin{tabular}{|c|c|c|c|c|}
\hline \multicolumn{5}{|c|}{ INHERITED FORMS OF DISTAL RENAL TUBULAR ACIDOSIS . MODIFIED BY6 } \\
\hline Inheritance & Age at presentation & Clinical features & Protein & Gene \\
\hline Dominant & Older /Adult & $\begin{array}{l}\text { Mild/compensated metabolic acidosis } \\
\text { Hypokalemia (variable) } \\
\text { Hypercalciuria } \\
\text { Hypocitraturia } \\
\text { Nephrolithiasis } \\
\text { Nephrocalcinosis } \\
\text { Sometimes rickets/osteomalacia } \\
\text { Secondary erythrocytosis }\end{array}$ & AE1 & SCL4A1 \\
\hline Recessive & Childhood & $\begin{array}{l}\text { Metabolic acidosis with hemolytic anemia } \\
\text { Only reported in Southeast Asian populations }\end{array}$ & AE1 & SCL4A1 \\
\hline Recessive with early onset hearing loss & Infancy/Childhood & $\begin{array}{l}\text { Metabolic acidosis } \\
\text { Early nephrocalcinosis } \\
\text { Vomiting/dehydration } \\
\text { Growth retardation } \\
\text { Rickets } \\
\text { Bilateral sensorineural hearing loss, } \\
\text { from childhood }\end{array}$ & $\begin{array}{l}\text { B1 subunit of } \\
\mathrm{H}^{+}-\text {ATPasi }\end{array}$ & ATP6V1B1 \\
\hline Recessive with late onset of hearing loss & Infancy/Childhood & $\begin{array}{l}\text { As above, but later onset hearing } \\
\text { loss in some } \\
\text { (a few with normal hearing) }\end{array}$ & $\begin{array}{l}\text { A4 subunit of } \\
\mathrm{H}^{+}-\text {ATPasi }\end{array}$ & ATP6V0A4 \\
\hline
\end{tabular}


We observed that the need for bicarbonate - as well as potassium citrate - had halved over time compared to the initial doses (fig. 2). Upon the last control (8 months), the baby weighed $6,950 \mathrm{Kg}$ and the metabolic balance was preserved.
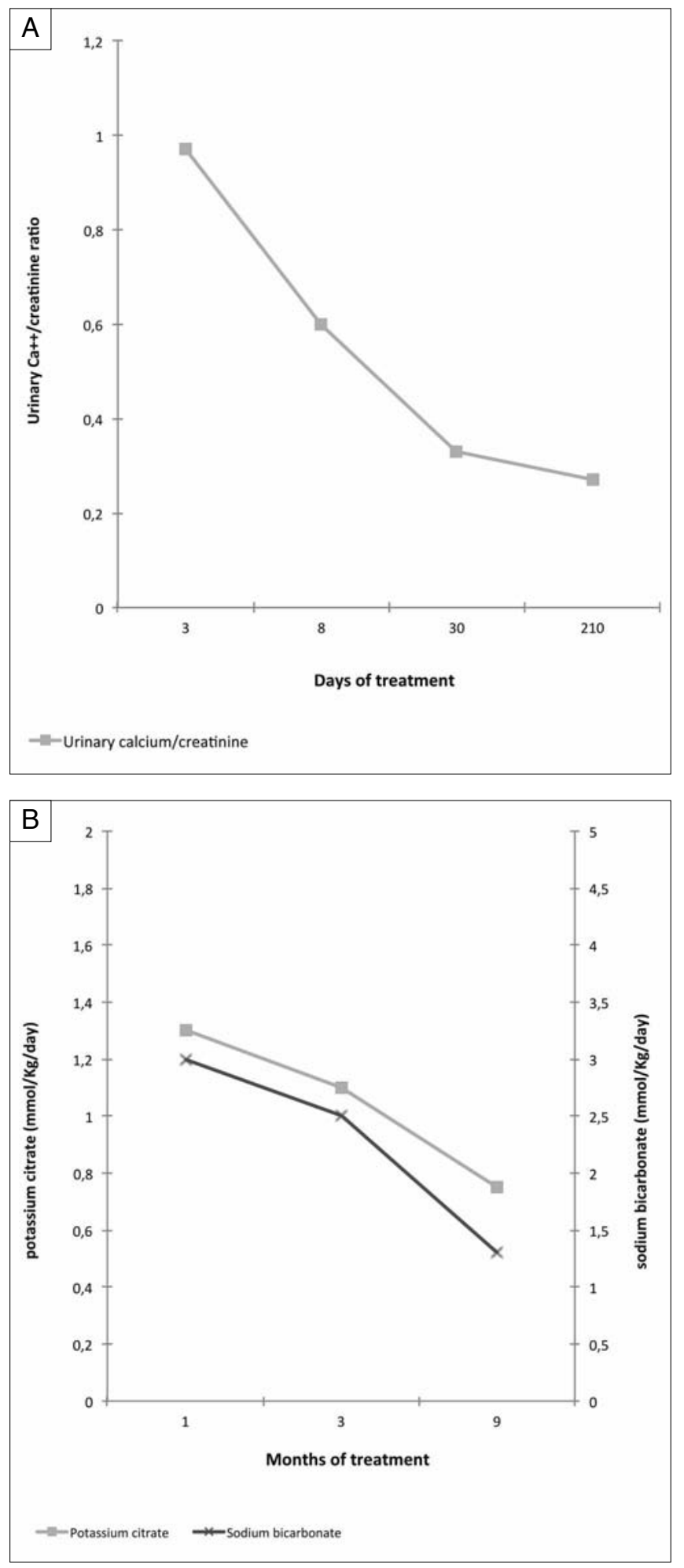

Figure 2.

a: Modifications of urinary calcium/creatinine ratio in first 30 days of therapy and during follow up.

b: Modifications of sodium bicarbonate and potassium citrate needs during first 9 months of treatment.

\section{Discussion}

Molecular genetic investigations performed in the families of patients with IRTA allowed for a better understanding of the physiological mechanism of urine acidification and defined genotype-phenotype correlation in different distal renal tubular acidosis forms (tab 1). Autosomal dominant dRTA is caused by mutations affecting the exchange $\mathrm{Cl}-/ \mathrm{HCO}-{ }_{3} \mathrm{AE} 1$, encoded by SLC4A1 gene. ${ }^{11}$ This protein is mainly expressed in erythrocytes (eAE1) and in kidneys (kAE1).

Even if these forms of distal tubular acidosis present themselves with common distal acidosis, they usually occur in late adolescence or adulthood, and with a milder clinical history compared to autosomal recessive forms (connected to mutations of $\mathrm{H}^{+} /$ATPase). ${ }^{12,13}$ These recessive forms have an early onset, (often during the first month of life), in the first or the second childhood with metabolic acidosis, hypokalemia, stopping growth, hypercalciuria and nephrocalcinosis. They cause rickets and stopping growth, that may lead to renal failure, if untreated or wrongly treated . An important prognostic element is the possible association with neurosensory hearing loss (NSHL).

Autosomal recessive dRTA were associated with $\mathrm{H}^{+} / \mathrm{ATP}$ ase $\mathrm{B} 1$ and A4 subunit mutations. Subunit B1 is coded by ATP6V1B1 gene located on chromosome 2q13. This protein is expressed in cochlear cells and in endolymphatic SAC, where it contributes to the maintenance of endolymphatic acid $\mathrm{pH}$. Several mutations altering the structure or abolishing the production of B1 subunit, with irreversible cochlear cell damage, were identified. $70-90 \%$ of patients with mutations of this subunit showed NSHL onset (within the tenth year of life). ${ }^{13,14}$

$\mathrm{H}^{+} /$ATPase A4 subunit is coded by ATP6V0A4 gene, located on chromosome 7 p33-34.

A recent study, carried out on 43 dRTA patients, showed that these protein mutations were associated with early NSHL onset in about $40 \%$ of patients. ${ }^{14}$ Therefore, unlike previous conclusions, the finding of A4 subunit dRTA mutation doesn't exclude the possibility of NSHL onset (even within the tenth year of life), thereby reconsidering the role of genetic investigations in early prognosis. The case presented had a very early onset with feeding difficulties and significant slowdown in growth since the early weeks of life, as demonstrated by the low weight increase (only 190 grams in 45 days). Upon onset, the metabolic acidosis was severe on average, associated with hypokalemia, hypercalciuria and bilateral nephrocalcinosis. Important signs were hypercalcemia and hyperphosphoremia, both plausible expression of bone mineral reabsorption, along with hyperammonemia, as already reported in other cases, due to ammonium ion deficient excretion. ${ }^{10}$

Anion gap was slightly increased $(\sim 16 \mathrm{mmol} / \mathrm{L})$ and this characteristic, which is not typical of dRTA, was probably caused by a transient hyperlactacidemia. Upon hospitalization, lactate concentration was $7.5 \mathrm{mmol} / \mathrm{L}$ compatible with a severe dehydration and mild systemic hypoperfusion. However, we had to consider the possibility of an underlying metabolic disease. The normality of lactate/pyruvate ratio, the absence of significant alterations of urine 
organic acids, urinary amino acids, blood amino acids made us rule out a metabolic disorder. Persistently elevated $\mathrm{pH}$ urinary values $(7,5)$ despite systemic metabolic acidosis, lead us to the diagnosis of an early-onset distal renal tubular acidosis. Treatment with sodium bicarbonate and potassium citrate has promptly corrected metabolic acidosis, hypokalemia and hypercalciuria (Fig. 2a).

Our patient presented a speedy recovery of weight and impaired growth, while alkali needs (calculated pro Kg of body weight) that was required to maintain metabolic balance, were gradually reduced during the first 9 months of treatment (Fig. 2b).

\section{Conclusions}

Negativity of audiometric screening leads us to exclude, until now, the involvement of the inner ear. For the future, it will be extremely important, whatever the results of genetic investigations might be, to schedule a regular follow-up with methodologies in line with the age of patients, in order to detect the first signs of a neurosensory hearing loss, which is key for the prognosis.

\section{References}

1 Pines KL, Mudge GH. Renal tubular acidosis with osteomalacia. Am J Med 1951; 11: 302-311.

2 Rodriguez-Soriano J. Renal tubular acidosis: the clinical entity. J AM Soc Nephrol 2002; 13:2160-2170.

3 Alper SL (2002) Genetic diseases of acid-base transporters. Annu Rev Physiol 64: 899-923.

4 Rodriguez Soriano J. New insight into the pathogenesis of renal tubular acidosis-From functional to molecular studies. Pediatr Nephrol 2000; 14:1121-1136.
5 Batlle DC, Ghanekar H, Jain S, Mitra A. Hereditary distal renal tubular acidosis:New understandings. Annu Rev Med 2001; 52:471-484.

6 Fry AC, Karet FE. Inherited renal acidoses. Physiology 2007; 22:202-211

7 Zakzouk SM, Sobki SH, Mansour F, al Anazy FH. Hearing impairment in association with distal renal tubular acidosis among Saudi children. J Laryngol Otol 1995; 109: 930-934

8 Oduwole AO, Giwa OS, Arogundade RA. Relationship between rickets and incomplete distal renal tubular acidosis in children. Ital J Ped 2010; 36:54-61

9 Sharma AP, Sharma RK, Kapoor R, Kornecki A, Sural S, Filler G. Incomplete distal renal tubular acidosis affects growth in children. Nephrol Dial Transplant 2007; 22: 2879-2885

10 Miller SG, Schwartz GJ. Hyperammonaemia with distal renal tubular acidosis. Arch Dis Child 1997; 77: 441-444.

11 Bruce LJ, Cope DL, Jones GK, Schofield AE, Burley M, Povey S, Unwin RJ, Wrong O, Tanner MJ. Familial distal renal tubular acidosis is associated with mutations in the red cell anion exchanger (Band 3, AE1) gene. J Clin Invest 1997; 100:1693-1707

12 Karet FE, Finberg KE, Nelson RD, Nayir A, Mocan H, Sanjad SA, Rodriguez-Soriano J, Santos F, Cremers CW, Di Pietro A, et al. Mutations in the gene encoding B1 subunit of $\mathrm{H}+$ /ATPase cause renal tubular acidosis with sensorineural deafness. Nat Genet 1999; 21:84-90

13 Stover EH, Borthwick KJ, Bavalia C, Eady N, Fritz DM, Rungroj N, et al. Novel ATP6V1B1 and ATP6V0A4 mutations in autosomal recessive distal renal tubular acidosis with new evidence for hearing loss. J Med Genet 2002; 796-803

14 Vargas-Poussou R, Houillier P, Le Pottier N, Strompf L, Loirat C, Baudouin V, Macher MA, et al. Genetic investigation of autosomal recessive distal renal tubular acidosis: evidence for early sensorineural hearing loss associated with mutations in the ATP6V0A4 gene. J Am Soc Nephrol 2006; 17:14371443 